\title{
Benefits, Burden, and COVID-19: A Response to Dutheil et al. (2020)
}

\author{
Eric Rubenstein ${ }^{1}\left[\right.$ ] Amy Kalkbrenner ${ }^{2} \cdot$ Heather Volk $^{3} \cdot$ Laura McGuinn $^{4}$
}

Accepted: 10 October 2020 / Published online: 21 October 2020

(c) Springer Science+Business Media, LLC, part of Springer Nature 2020

To the editor,

The COVID-19 pandemic is having, and will continue to have, major impacts on individuals with intellectual and developmental disabilities (IDD), including autism spectrum disorder (ASD). Dutheil et al. have hypothesized that one such impact will be a reduction of ASD risk in children conceived during the pandemic. The authors hypothesize that due to a period with a reduction in air pollution (due to quarantine orders that reduced driving and economic activity) there will be a decreased risk of ASD. There is a considerable literature that find high levels of air pollution are modestly associated with increased occurrence of ASD in children (McGuinn et al. 2020; Kalkbrenner et al. 2018; Volk et al. 2013; Lam et al. 2016), and logically, a decrease in air pollution could reduce ASD risk. However, Dutheil et al. fail to consider the concomitant increase in other ASDrisk factors and fail to place potential 'benefits' in the context of the disproportionate burden the COVID-19 pandemic has placed on people on the spectrum and their families.

Many maternal factors during pregnancy are associated with elevated risk of ASD and plausibly have increased during the COVID-19 pandemic: stress (Beversdorf et al. 2018), maternal mental health conditions (Hagberg et al. 2018), malnutrition (Vohr et al. 2017), and alcohol and cigarette use (Lyall et al. 2017). In addition, there is a consistent literature from both animal and human studies regarding the role of maternal immune activation in the etiology of ASD (Estes

Eric Rubenstein

erubens@bu.edu

1 Department of Epidemiology, Boston University School of Public Health, Rm T318E 715 Albany St, Boston, MA 02121, USA

2 Department of Epidemiology, University of Wisconsin-Milwaukee Zilber School of Public Health, Milwaukee, USA

3 Department of Mental Health, Johns Hopkins Bloomberg School of Public Health, Baltimore, USA

4 Department of Environmental Medicine and Public Health, Icahn School of Medicine at Mount Sinai, New York, USA and McAllister 2016), which includes specific constructs of fever and infection (Zerbo et al. 2014; Croen et al. 2019). Currently, the effects of vertical transmission or COVID-19 while pregnant are unknown, but likely harmful (Rajewska et al. 2020). COVID-19 may lead to increased risk of poor birth outcomes (e.g. preterm birth, low birthweight) (Gao et al. 2020) which can increase risk of ASD (Lyall et al. 2017). Further upstream, we can hypothesize that a loss of income (Gilman et al. 2017) and delay in elective procedures and health care visits due to hospital overload (Diaz et al. 2020) can set off etiologic pathways that harm child neurodevelopment. While a reduction in air pollution may cause population-level reduction in ASD risk in a vacuum, the increase in many other risk factors, while unknown, may be substantial. Therefore, it is misleading and likely inaccurate to suggest a reduction in ASD risk because one risk factor may be reduced.

Dutheil et al. focused on one aspect in which COVID19 intersects with ASD: the risk of ASD for future cohorts of children. Although outside the scope of their letter, we believe that in the context of any 'benefits' of COVID-19 it is important to acknowledge the catastrophic impact of COVID-19 on persons living with ASD and other IDD. We know that COVID-19 outcomes and access to treatment are worse for marginalized populations (Tai et al. 2020; Laurencin and McClinton 2020). While we are only beginning to document impacts for communities living with IDD, to date we know that in the New York City region, adults with IDD living in residential care facilities had over three times the case rate and two times the case fatality rate as compared to other New York residents (Landes et al. 2020). The move to online schooling has exacerbated the inequities in special education and likely delayed crucial early intervention services for children with ASD (Ameis et al. 2020). These are two of countless examples of the impact felt in the IDD community and it is likely that the disproportionate burden of COVID-19 will have long lasting negative effects on health and well-being for people with ASD, other IDD, and their families. 
The authors write 'COVID-19 might have some benefits for future newborns with a decreasing risk of autism because of the reduction of air pollution, and may also have other health benefits on future newborns and mothers, such as avoiding a low-weight at birth, preterm birth, stillbirth, preeclampsia, or gestational diabetes' glossing over the global trauma of COVID-19 and discounts the possible role of the infection itself, let alone the psychosocial impacts of the pandemic. Studying the many facets of COVID-19, including air pollutant reductions, on the development and course of ASD will be an important area to study in order to learn more about etiology of ASD and how to better prepare for a public health crisis. However, any discussion of 'benefits' of the COVID-19 pandemic need to be placed in the context of the overwhelming harms.

Author Contributions ER conceptualized and wrote the first draft of the manuscript. AK, HV, and LM edited and added input to subsequent drafts.

\section{References}

Ameis, S. H., Lai, M. C., Mulsant, B. H., \& Szatmari, P. (2020). Coping, fostering resilience, and driving care innovation for autistic people and their families during the COVID-19 pandemic and beyond. Molecular Autism, 11(1), 61. https://doi.org/10.1186/ s13229-020-00365-y

Beversdorf, D. Q., Stevens, H. E., \& Jones, K. L. (2018). Prenatal stress, maternal immune dysregulation, and their association with autism spectrum disorders. Current Psychiatry Reports, 20(9), 76. https://doi.org/10.1007/s11920-018-0945-4

Croen, L. A., Qian, Y., Ashwood, P., Zerbo, O., Schendel, D., PintoMartin, J., et al. (2019). Infection and fever in pregnancy and autism spectrum disorders: Findings from the study to explore early development. Current Psychiatry Reports, 12(10), 15511561. https://doi.org/10.1002/aur.2175

Diaz, A., Sarac, B. A., Schoenbrunner, A. R., Janis, J. E., \& Pawlik, T. M. (2020). Elective surgery in the time of COVID-19. American Journal of Surgery, 219(6), 900-902. https://doi.org/10.1016/j. amjsurg.2020.04.014

Estes, M. L., \& McAllister, A. K. (2016). Maternal immune activation: Implications for neuropsychiatric disorders. Science, 353(6301), 772-777. https://doi.org/10.1126/science.aag3194

Gao, Y. J., Ye, L., Zhang, J. S., Yin, Y. X., Liu, M., Yu, H. B., et al. (2020). Clinical features and outcomes of pregnant women with COVID-19: A systematic review and meta-analysis. BMC Infectious Diseases, 20(1), 564. https://doi.org/10.1186/s12879-02005274-2

Gilman, S. E., Hornig, M., Ghassabian, A., Hahn, J., Cherkerzian, S., Albert, P. S., et al. (2017). Socioeconomic disadvantage, gestational immune activity, and neurodevelopment in early childhood. Proceedings of the National Academy of Sciences of the United States of America, 114(26), 6728-6733. https://doi.org/10.1073/ pnas. 1617698114
Hagberg, K. W., Robijn, A. L., \& Jick, S. (2018). Maternal depression and antidepressant use during pregnancy and the risk of autism spectrum disorder in offspring. Clinical Epidemiology, 10, 15991612. https://doi.org/10.2147/clep.S180618

Kalkbrenner, A. E., Windham, G. C., Zheng, C., McConnell, R., Lee, N. L., Schauer, J. J., et al. (2018). Air toxics in relation to autism diagnosis, phenotype, and severity in a U.S. family-based study. Environmental Health Perspectives, 126(3), 037004. https://doi. org/10.1289/EHP1867

Lam, J., Sutton, P., Kalkbrenner, A., Windham, G., Halladay, A., Koustas, E., et al. (2016). A systematic review and meta-analysis of multiple airborne pollutants and autism spectrum disorder. PLoS ONE, 11(9), e0161851. https://doi.org/10.1371/journ al.pone. 0161851

Landes, S. D., Turk, M. A., Formica, M. K., McDonald, K. E., \& Stevens, J. D. (2020). COVID-19 outcomes among people with intellectual and developmental disability living in residential group homes in New York State. Disability and Health Journal. https:// doi.org/10.1016/j.dhjo.2020.100969

Laurencin, C. T., \& McClinton, A. (2020). The COVID-19 pandemic: A call to action to identify and address racial and ethnic disparities. Journal of Racial and Ethnic Health Disparities, 7(3), 398 402. https://doi.org/10.1007/s40615-020-00756-0

Lyall, K., Croen, L., Daniels, J., Fallin, M. D., Ladd-Acosta, C., Lee, B. K., et al. (2017). The changing epidemiology of autism spectrum disorders. Annual Review of Public Health, 38, 81-102. https:// doi.org/10.1146/annurev-publhealth-031816-044318

McGuinn, L. A., Windham, G. C., Kalkbrenner, A. E., Bradley, C., Di, Q., Croen, L. A., et al. (2020). Early life exposure to air pollution and autism spectrum disorder: Findings from a multisite case-control study. Epidemiology, 31(1), 103-114. https://doi. org/10.1097/EDE.0000000000001109

Rajewska, A., Mikołajek-Bedner, W., Lebdowicz-Knul, J., Sokołowska, M., Kwiatkowski, S., \& Torbé, A. (2020). COVID-19 and pregnancy - where are we now? A review. Journal of Perinatal Medicine, 48(5), 428-434. https://doi.org/10.1515/jpm-2020-0132

Tai, D. B. G., Shah, A., Doubeni, C. A., Sia, I. G., \& Wieland, M. L. (2020). The disproportionate impact of COVID-19 on racial and ethnic minorities in the United States. Clinical Infectious Diseases. https://doi.org/10.1093/cid/ciaa815

Vohr, B. R., Poggi Davis, E., Wanke, C. A., \& Krebs, N. F. (2017). Neurodevelopment: The impact of nutrition and inflammation during preconception and pregnancy in low-resource settings. Pediatrics, 139(Suppl 1), S38-s49. https://doi.org/10.1542/ peds.2016-2828F

Volk, H. E., Lurmann, F., Penfold, B., Hertz-Picciotto, I., \& McConnell, R. (2013). Traffic-related air pollution, particulate matter, and autism. JAMA Psychiatry, 70(1), 71-77. https://doi. org/10.1001/jamapsychiatry.2013.266

Zerbo, O., Yoshida, C., Grether, J. K., Van de Water, J., Ashwood, P., Delorenze, G. N., et al. (2014). Neonatal cytokines and chemokines and risk of Autism Spectrum Disorder: the Early Markers for Autism (EMA) study: A case-control study. Journal of Neuroinflammation, 11, 113. https://doi. org/10.1186/1742-2094-11-113

Publisher's Note Springer Nature remains neutral with regard to jurisdictional claims in published maps and institutional affiliations. 